\title{
Accuracy of Skill Performance in the Basketball Free Throw Shooting
}

\author{
Takayuki Watanabe ${ }^{*}$ Takeshi Sato ${ }^{* \dagger}$ Shoji Igawa ${ }^{\ddagger}$ \\ (*)Hachinohe University, Japan \\ (*) Jissen Women's University, Japan \\ (†)Nippon Sport Science University, Japan \\ E-mail: nabetaka@hachinohe-u.ac.jp,sato-takeshi@jissen.ac.jp,igawa@nittai.ac.jp
}

\begin{abstract}
The purpose of this study were to investigates how timing of shot of skilled player and assess performance accuracy of free throw shooting. Ten college students participated in this study (5 skilled players, and 5 naïve participants) aged 18-23 years. They performed free throw shooting at 10 times. Shooting seen was recorded three cameras and analyzed shooting successful rate, off-target distance (the distance between the basketball through point and the center of the goal) and shot timing. Shot timing was not significant difference. Shooting successful rate of skilled players was higher than unskilled players. Offtarget distance of skilled players was significant smaller than naive player. Consequently, skilled player is possible to aim at the center of the goal and shooting near the center of goal.
\end{abstract}

\section{Introduction}

The goal of basketball is above the line of vision. It is necessary to forecast the fall point of ball when you are shooting. Therefore, shooting accuracy and the relation of the visual control [1], biomechanics researches [2] have been done. However, shooting accuracy using distance from center of target was not researched. This skill is like to target sports as darts, but it is necessary to acknowledge the space that the goal is existence even level of the ground. It is necessary to move and coordinate the body each part, such as elbow and wrist, knee and hip joint to improve the shot skill of basketball, and to consider the distance to the goal, and it necessary to output power.

Button et al [3]. report the movement variability in the basketball free throw action at different skill levels. There were defined trajectory variability and joint segments of the throwing arm. However movement variable mainly evaluated the value between individuals. Also, it was not investigated the whole motion during a basketball free throw shooting.

Therefore, the purpose of this study were investigates to timing error of shot of skilled player and assess skill performance accuracy of free throw shooting using the distance between the basketball through point and the center of the goal.

\section{Method}

\subsection{Subjects}

Subjects were five basketball players (skilled player) aged 18-23 years and five students with no basketball experience (naïve participants) aged 19-22 years. All subjects were right handed and they had not injured in the past. Informed consent was completed by all subjects before the experiment. The skilled player had played basketball competitively $8-14$ years $(11.6 \pm$ 2.5 years), and one of them was belong to pro basketball team (BJ league) as foster player in Japan.

\subsection{Experimental set up}

A schematic representation of the experimental set up is shown Fig. 1. After a warm up, subjects were asked to try to shoot the basketball through the ring without the ball touching to the goal. For the shooting, subjects were not exceeded free throw line. And also they kept their feet in contact with the ground. The goal of basketball was $0.45 \mathrm{~m}$ in the diameter placed $3.05 \mathrm{~m}$ above the floor and $4.25 \mathrm{~m}$ from free throw line. The basketball was used size 7 (BGL 7, Molten ).

Subjects were instructed to take aim and through the goal to best of their skill. They performed free throw shooting at 10 times. The trials per subjects were record three cameras. Two cameras (camera A, and B) (DCR-HC1000, SONY) aimed at the goal from a place $10 \mathrm{~m}$ away. Filming rate was $30 \mathrm{~Hz}$. Another camera

This is an Open Access article distributed under the terms of the Creative Commons Attribution-Noncommercial License 3.0, which permits unrestricted use, distribution, and reproduction in any noncommercial medium, provided the original work is properly cited. 
(EX-FH100, CASIO) took a picture of the shooting movement at $120 \mathrm{~Hz}$ from a place $10 \mathrm{~m}$ away.

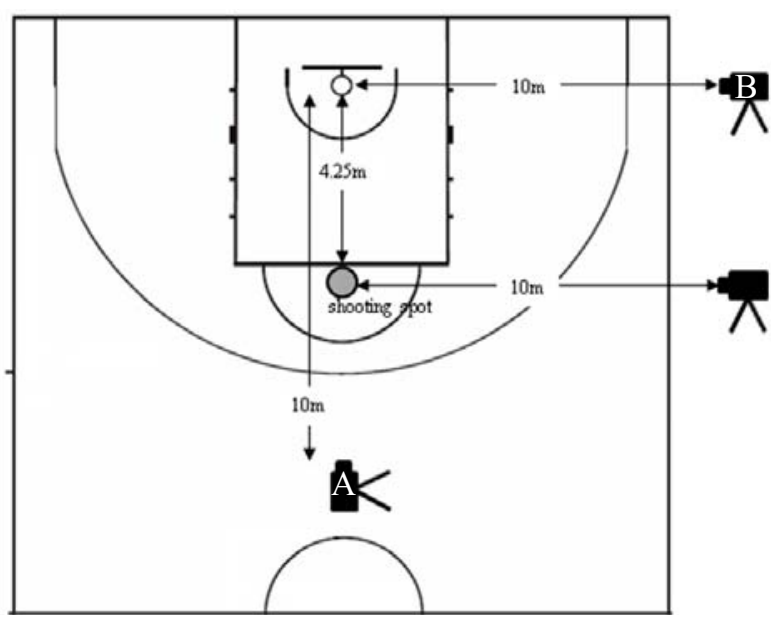

Fig. 1. Experimental set up

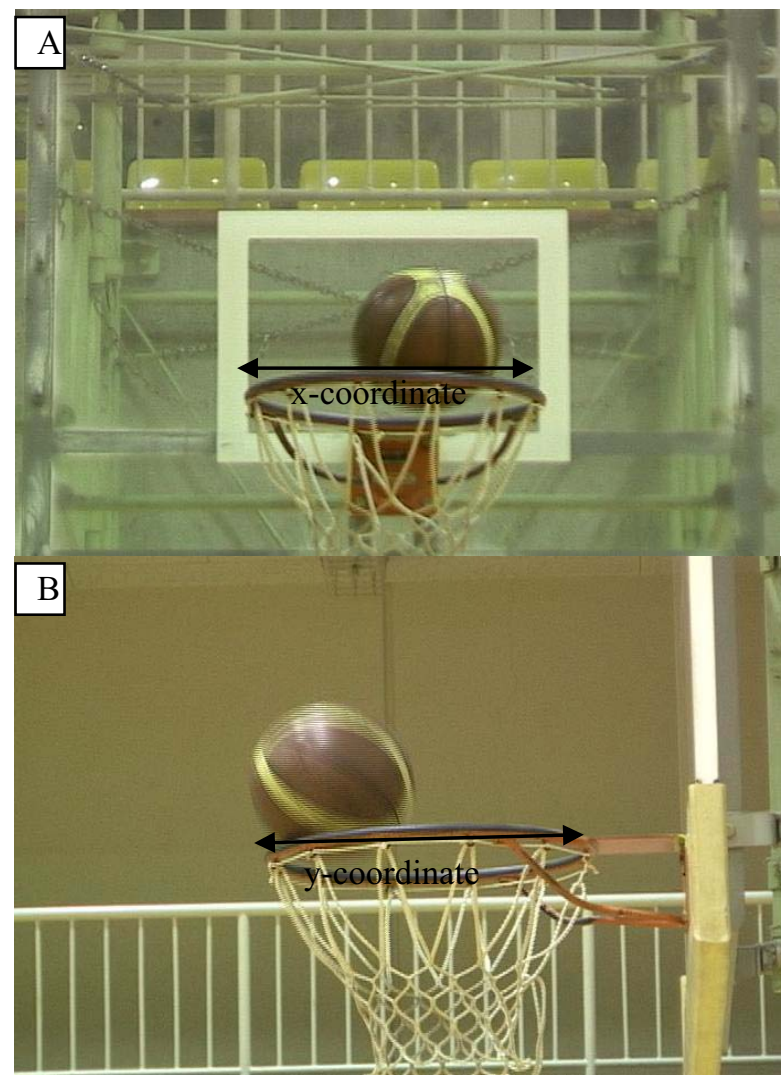

Fig. 2. The $\mathrm{x}$ - and $\mathrm{y}$-coordinates of the goal area were searched for computer. X-coordinates were measured from the image of camera $\mathrm{A}$, and the distance on either side was calculated from obtained data. Y-coordinates were measured from the image of camera $B$, and the distance of depth was calculated from the obtained data.

\subsection{Data analysis}

Shooting skill performance evaluated the point where it had passed over the goal. In addition, we measured the $\mathrm{x}$ - and $\mathrm{y}$-coordinates on the goal area (Fig. 2.). From these values, the off-target distance [4] (the distance between the basketball through point and the center of the goal) was calculated. Shooting successful rate and shot timing were calculated.

Timing of shot was normalized from starting of ball move to ball release, and indicate the percentage (Fig. 3.). Shooting movement was analyzed to divide the knee bent position and the ball set position. Error range of movements were analyzed two position.

\subsection{Statistical analysis}

The shooting successful rate, off-target distance and error margin of shot timing of the skilled and naïve participants were compared an independent t-test. Significance was set at $P<0.05$.

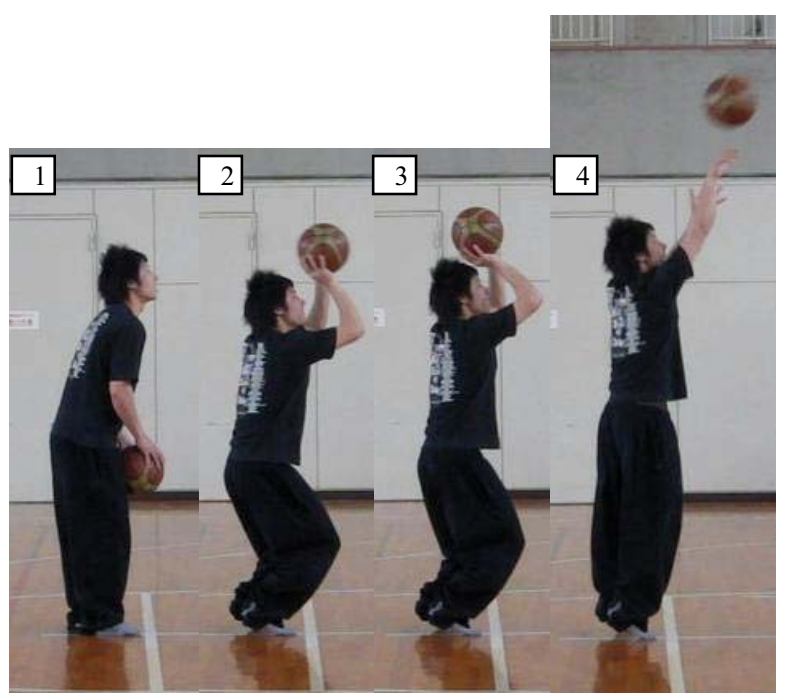

Fig. 3. Typical shooting movement of basketball to skilled player. 1 is ready position, 2 is knee bent position, 3 is ball set position and 4 is ball release position. These position was normalized from $1=0 \%$ to $4=100 \%$.

\section{Result}

Fig. 4. showed shooting successful rate. Shooting successful rate of skilled player was significant higher than naïve participants. Fig. 5. showed off-target distance. Off-target distance of skilled player was significant smaller than naïve participants. 
Error margin of shot timing for knee bent position and ball set position was indicated Table. 1. Both position of error margin for skilled player were not significant difference to naïve participants.

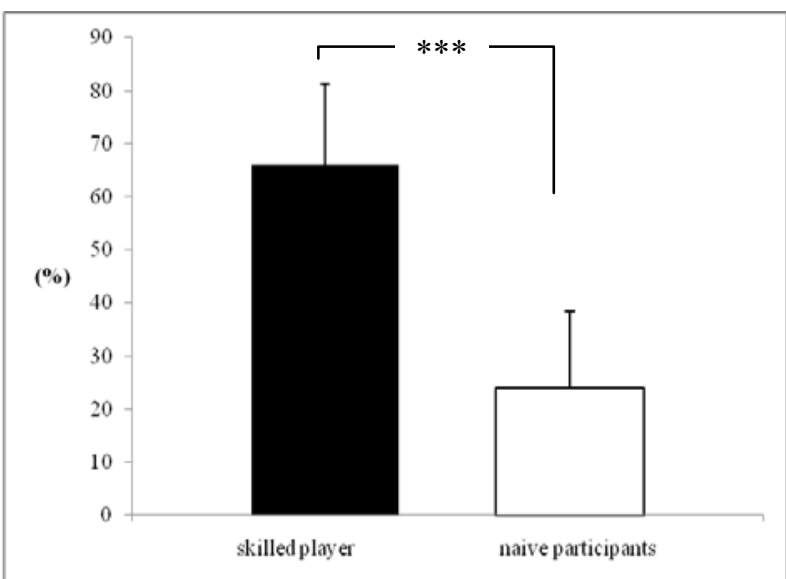

Fig.4. shooting successful rate. Black bar (๘) indicate skilled player, White bar ( $\square$ ) indicate naïve participants. ${ }^{* * *} P<0.001$

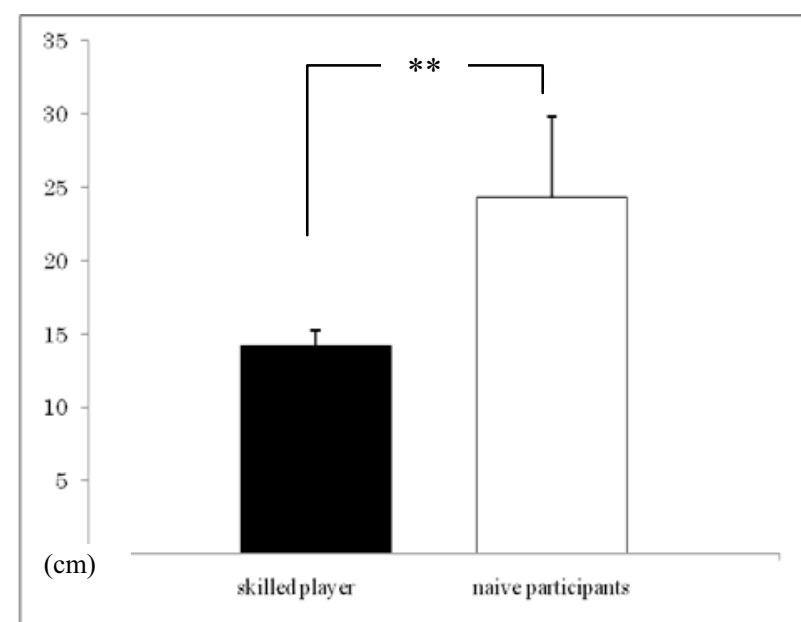

Fig. 5. Off-target distance. Black bar (ם) indicate skilled player, White bar ( $\square$ ) indicate naïve participants. ${ }^{* *} P<0.01$

Table. 1. Error margin of shot timing for knee bent position and ball set position.

\begin{tabular}{lrlrl}
\hline & knee bent position & \multicolumn{2}{c}{ ball set position } \\
\hline $\begin{array}{l}\text { skilled } \\
\text { player }\end{array}$ & 8.0 & $\pm 4.5 \% \mathrm{n.s}$ & 6.4 & $\pm 3.8 \%$ n.s. \\
$\begin{array}{l}\text { naïve } \\
\text { participants }\end{array}$ & 12.8 & $\pm 9.6 \%$ & 10.8 & $\pm 6.6 \%$ \\
\hline
\end{tabular}

\section{Discussion}

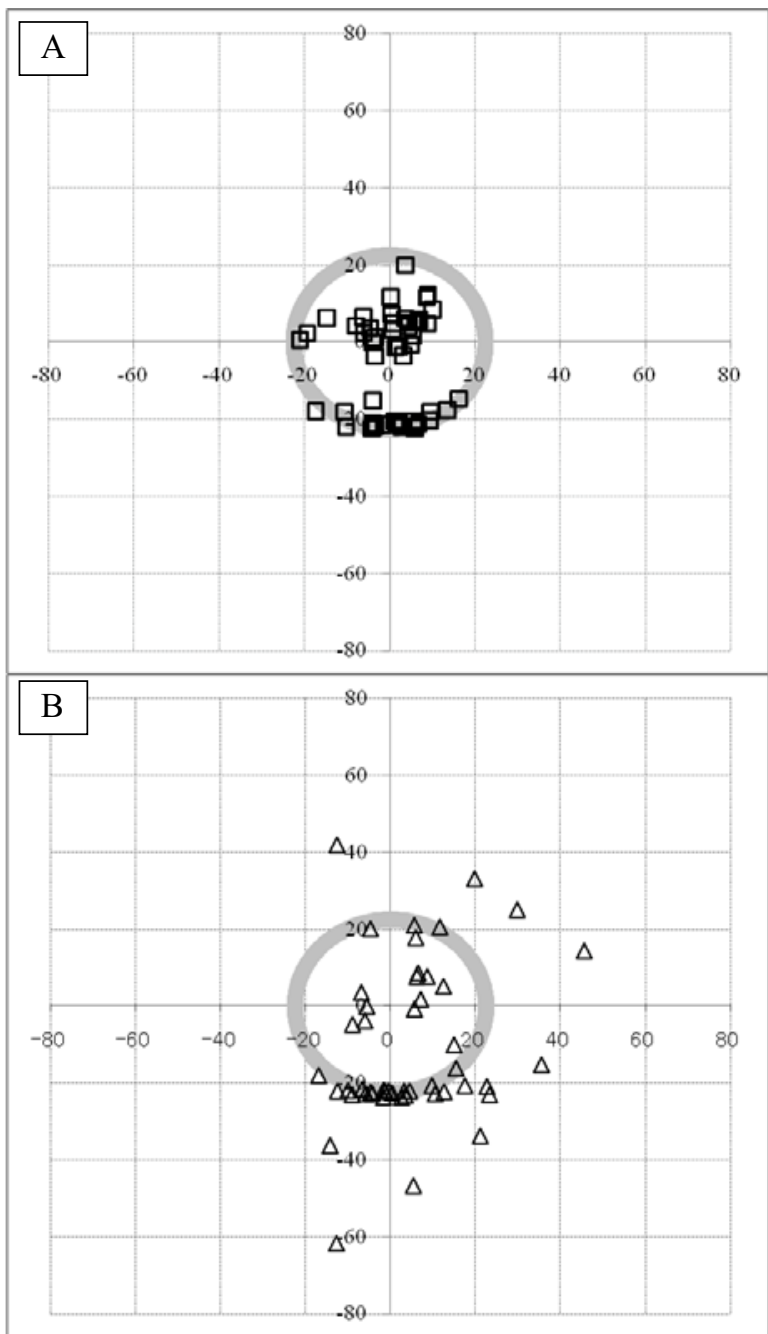

Fig. 6. ball through and hit the goal position of skilled player (A) and naïve participants ( B).

This study were investigates to timing error of shot of skilled player and assess performance accuracy of free throw shooting using the distance between the basketball through point and the center of the goal.

Error margin of timing of shot for both positions at skilled player was not significant difference for naïve participants. This result means that the player was always adjusting the timing of shot regardless of skill level. Because both player had not success of shot, and they should change the effort force to the ball. Although, the one player was different. His shoot successful rate was $90 \%$, and it had get through the goal without the touch a ring in many cases. And the error of shooting movement of the both positions was smaller than whom of other players. It was considered 
that little error of shooting movement was making the shot successful at the always same place.

Shooting successful rate of skilled player was significant higher than naïve participants. And offtarget distance of skilled player was significant smaller than naïve participants. Fig. 6. were indicate of ball through and hit the goal positions after the free throw of skilled and naïve participants. The points of skilled player were gathers in the center or front of goal. On the other hand, distribution of naïve participants were widely, the ball not only reaches but also to shift sideways greatly, and gather the front of goal. It was because the ball was not controlled, and the skill that guesses the distance of the space has not been acquired. When shooting the ball, the goal of basketball has target on its eyes, and it existence even level of the ground. For this reason, the shooter was difficult to have a clue about distance, for the vision was reflected upward at front side of ring, and downward at back side of ring. Moreover, it was considered that the ball hit to front side of the goal in order to focused ring of front side was easy.

Consequently, it was suggested that skilled player was superior to capability for cognitive of space and could coordinate to output of force.

\section{Conclusion}

This study were investigates to timing error of shot of skilled player and assess performance accuracy of free throw shooting using the distance between the basketball through point and the center of the goal. Shooting successful rate of skilled player was significant higher than naïve participants. Off-target distance of skilled player was significant smaller than naïve participants. Skilled players were gathers in the center or front of goal. Distribution of naïve participants were widely. Error margin of shot timing for knee bent position and ball set position was not significant difference at both participants.

\section{References}

[1] R.D. Oudejans, R.W. Langenberg, and R.I. Hutter, Aiming at a far target under different viewing conditions: Visual control in basketball shooting, Human movement Science, 21, 457-480. 2002

[2] S. Miller and R. Bartlett, The relationship between basketball shooting kinematics, distance and playing position, Journal of sports sciences, 14, 243-253. 1996

[3] C. Button, M. MacLeod, R. Sanders and S. Coleman, Examining movement variability in the basketball free throw action at different skill levels, Research quarterly for exercise and sport, 74, 3, 257-259, 2003

[4] S. Sakurai and T. Ohtsuki, Muscle activity and accuracy of performance of the smash stroke in badminton with reference to skill and practice, Journal of sports sciences, 18, 901-914. 2000 